Running head: FORM SHIFT EFFECTS ON MORPHOLOGICAL PRIMING

\title{
Effects of Phonological and Orthographic Shifts on Children's Processing of Written Morphology: a Time-Course Study
}

Pauline Quémart and Séverine Casalis

\section{Accepted for publication in Scientific Studies of Reading}

Pauline Quémart : University of Poitiers and Centre National de la Recherche Scientifique, MSHS, Bâtiment A5, 5 rue Théodore Lefebvre, 86000 Poitiers, France, and University of Lille North of France, Research Unit in Cognitive and Affective Sciences, Université Charles de Gaulle Lille 3, 59653 Villeneuve d'Ascq, France pauline.quemart@univ-poitiers.fr; (+33)(0)5.49.45.46.19

Séverine Casalis : University of Lille North of France, Research Unit in Cognitive and Affective Sciences, Université Charles de Gaulle Lille 3, 59653 Villeneuve d'Ascq, France severine.casalis@univ-lille3.fr; (+33)(0)3.20.41.63.69

Acknowledgements. This research was completed while the first author was a doctoral student at the University of Lille North of France and was supported by the French Ministry of Research and Technology (award to P. Quémart) and by the French National Agency of Research (project "Lect Morpho", award to S. Casalis). We are grateful to the children and the University students who participated in this study. We would like to thank the three anonymous reviewers for their helpful comments and suggestions. 


\begin{abstract}
We report two experiments that investigated whether phonological and/or orthographic shifts in a base word interfere with morphological processing by French third, fourth and fifth graders and adults (as a control group) along the time course of visual word recognition. In both experiments, prime-target pairs shared four possible relationships: morphological without modification (nuageux-NUAGE), morphological with phonological modification (bergerie-BERGER), morphological with phonological and orthographic modifications (soigneux-SOIN) and orthographic control (fourmi-FOUR). In Experiment 1 (60-ms prime duration), priming effects were only significant in the morphological condition without modification in children, but in the three morphological conditions in adults. In Experiment 2 (250-ms prime duration) priming effects were significant in all three morphological conditions in each group, independently of form shifts. These results indicate that allomorphic variation does allow for the lexical activation of base words only in the later stages of word recognition in children, whereas this activation is automatic in adults.
\end{abstract}

Abstract wordcount $=150$ 


\section{Effects of Phonological and Orthographic Shifts on Children's Processing of Written}

\section{Morphology: A Time-Course Study}

The influence of morphological information on visual word recognition has received constant attention from researchers since the 1970s. Over the past decade, our knowledge of whether, how and under which conditions morphologically complex words are broken down into smaller components during reading has grown exponentially (for a recent review, see Amenta \& Crepaldi, 2012). Many studies have examined the influence of the semantic dimensions of morphemes on visual word recognition in both skilled readers (Feldman, Soltano, Pastizzo, \& Francis, 2004; Longtin, Segui, \& Hallé, 2003; Marslen-Wilson, Tyler, Waksler, \& Older, 1994) and developing readers (Beyersmann, Castles, \& Coltheart, 2012; Quémart, Casalis, \& Colé, 2011). Recently, the focus has turned to the influence of morphemes' form (i.e., orthographic and phonological) dimensions (Crepaldi, Rastle, Coltheart, \& Nickels, 2010; McCormick, Rastle, \& Davis, 2008). The goal of the present study was thus to examine how developing readers process the phonological and orthographic dimensions of morphemes during visual word recognition.

Understanding how developing readers encode the form dimensions of morphemes is particularly relevant for two reasons. The first one is empirical: a substantial number of morphologically complex words are constructed from a base word that undergoes orthographic and/or phonological alteration during the derivation process (e.g., five-fifty). It is therefore important to identify the mechanisms by which developing readers deal with such allomorphic variation. The second argument is theoretical: the morphological structure of words has been shown to play a critical role in lexical access across a wide range of studies (Amenta \& Crepaldi, 2012). However, the issue of whether morphemic allomorphs activate their base word during lexical access has yet to be resolved in the case of developing readers. 
As written language is a representation of spoken language, literacy involves the integration of oral and written language skills (Gough \& Tunmer, 1986; Nation \& Snowling, 2004). As a consequence, children's ability to develop oral morphological representations by detecting morphological relationships between spoken words may be a critical factor in their development of written morphological representations. A large body of research supports the idea that morphological awareness (i.e., the ability to understand and manipulate the smallest language units of meaning within words) is required for successful reading development (e.g., Kirby et al., 2012). In addition, according to Schreuder and Baayen (1995), phonological transparency (i.e., the degree of base word preservation within derived forms) is a critical factor in the development of both oral and written representations of morphology. Children's processing of written morphology may thus be influenced by their ability to detect morphological relationships between spoken words, and the phonological stability of the base in the derived form may play an important role in this context.

The orthographic information encoded in morphemes is also useful when developing morphological representations. One plausible hypothesis explaining children's ability to develop representations for written morphology has come from Rastle and Davis (2008; see also Verhoeven \& Perfetti, 2011), who postulate that children learn to capture systematic relationships between word form and meaning. When a reader detects that a given letter string is consistently associated with the same meaning, he/she develops a mental representation of this string (i.e., morpheme) in terms of both form (orthography and phonology) and meaning. In this context, the orthographic stability of morphemes in the base and derived forms may be extremely important when developing written morphological representations.

\section{Influence of Phonological and Orthographic Shifts on Morphological Decomposition}

Previous studies have yielded evidence for the negative impact of orthographic and phonological modifications to the base on children's word reading. English-speaking third 
and fifth graders perform significantly less well when naming shift words (e.g., curiosity) than stable words (e.g., suddenly), indicating that their reading is affected by form modifications to the base (Carlisle, 2000). Similar results have been reported by Mann and Singson (2003) for third and fourth graders, but not for fifth and sixth graders. Deacon, Campbell, Tamminga, and Kirby (2010) extended this research by showing that form transparency influences the reading accuracy of fourth and sixth graders, but not their naming speed. Orthographic and phonological shifts in the base also have an impact in tasks that do not explicitly require the activation of phonological codes. In a lexical decision task, for instance, Carlisle and Stone (2005) showed that complex words that had undergone a phonological or orthographic shift were accepted more slowly than stable complex words.

However, the influence of form modifications on children's word reading can be interpreted in two ways. Either morphologically complex shift words are processed through their components, in which case form shifts hinder their morphological decomposition in terms of response speed or accuracy, or they are not processed through their components, in which case lexical access takes place via whole-word representations, just as it would for any morphologically simple word. One way of deciding between these interpretations is to compare the priming potential of stable and shift complex words with that of monomorphemic words.

\section{The Priming Paradigm as a Tool for Tracking the Influence of Morphemes' Form}

\section{Properties}

The priming paradigm with a lexical decision task has proved to be a useful tool for investigating the impact of morphemes' form properties on visual word recognition in adults (Järvikivi \& Pyykkönen, 2011; Longtin et al., 2003; Marslen-Wilson, Bozic, \& Randall, 2008; Rastle \& Davis, 2008; Rastle, Davis, \& New, 2004). Derived primes facilitate target recognition when one of the letters in the prime's base word is duplicated (e.g., dropper- 
DROP), or deleted (e.g., adorable-ADORE; McCormick et al., 2008). Irregularly inflected words also prime their base (e.g., fell-FALL), unlike orthographically related words (e.g., fillFALL, Crepaldi et al., 2010). Even though there are substantial differences between derivational and inflectional priming, these priming patterns indicate that allomorph primes do activate their base word very early in the time course of visual word recognition in skilled readers.

The primed lexical decision task has also been used to investigate the processing of morphemes' form and meaning properties in developing readers (Beyersmann et al., 2012; Quémart et al., 2011). In a priming study with manipulation of prime duration, Quémart et al. (2011) were able to dissociate the influence of the morphemes' form properties from that of their meaning properties during morphological processing by third to seventh graders. When primes were displayed for $60 \mathrm{~ms}$, significant priming effects occurred in both the morphological (e.g., in English: singer-SING) and pseudoderivation (morphological relationship without meaning; e.g., in English, corner-CORN) conditions. Similar priming patterns were observed when primes were displayed for $250 \mathrm{~ms}$, except that the amount of priming was significantly greater in the morphological condition than in the pseudoderivation one. Finally, with a prime duration of $800 \mathrm{~ms}$, only morphological and semantic (e.g., in English: tulip-FLOWER) relationships led to significant priming effects. These results were taken to suggest that developing readers are more influenced by morpheme's form dimensions at the beginning of word recognition, and by their semantic dimensions later in the time course $^{1}$. Each dimension is processed by a different procedure associated with a specific level

\footnotetext{
${ }^{1}$ Note that pseudoderivation masked priming effects were not replicated in a study by Beyersman et al. (2012), which might be explained by several fundamental differences between the two studies, such as the language used, prime length, prime duration and the mixing of inflectional and derivational primes in Beyersman et al. (2012)
} 
of representation (Diependaele, Sandra, \& Grainger, 2005, 2009): a morpho-orthographic procedure that is sensitive to morphemes' form dimensions but blind to their semantic dimensions, and a morpho-semantic procedure that relies on morphemes' semantic dimensions.

As processing the morphemes' form dimensions is so crucial at the start of the word recognition time course, the process by which developing readers deal with allomorphic variation needs to be properly understood. Two priming studies have examined the influence of form modifications on the processing of written morphology in children. Feldman, Rueckl, DiLiberto, Pastizzo, and Vellutino (2002) asked fifth graders to perform a primed fragment completion task. The students were more successful at completing a word fragment (e.g., $\left.m \_s \_[m e s s]\right)$ when it was preceded by a morphologically related word (e.g., MESSY) than when it was preceded by an orthographic control word (e.g., MESSAGE). Importantly, the probability of correctly completing the fragment was slightly higher when the derived form requiring completion was stable rather than shifted (e.g., BROKE - bre _ [break]). Even though this task does not directly probe visual word recognition, it can give us an idea of how base-word shifts negatively affect the processing of derived forms. In another study, Schiff, Raveh, and Kahta (2008) asked Hebrew-speaking third and seventh graders to perform a primed naming task with a 50-ms priming duration. Results showed that the prime helped the children to name the target when there was a total form overlap between these two items, but no priming effect was observed when the form overlap was only partial. Thus, the form overlap between morphologically related words is a critical factor for triggering morphological decomposition in Hebrew-speaking children.

\section{Overview of the Present Study}

The aim of the present study was to investigate whether, and at what point in the time course of word recognition, phonological and orthographic shifts in a base word interfere with 
morphological decomposition in children (third, fourth and fifth graders) learning to read in French. We also tested a group of adults, as such manipulation had never been done in French. The following three research questions were addressed:

1. Does morphological decomposition occur in spite of phonological and orthographic shifts in the base word?

2. Does the influence of form shifts vary according to reading expertise?

3. Does the influence of form shifts change across the time course of word recognition?

To examine these issues, we used the primed lexical decision task to compare priming patterns in four conditions: morphological without modification of the base (nuageux$N U A G E$ ); morphological with phonological modification of the base (bergerie-BERGER); morphological with phonological and orthographic modification of the base (soigneux-SOIN); and monomorphemic orthographic controls (fourmi-FOUR). In order to track the influence of form shifts across the time course of visual word recognition, we manipulated prime duration. In their time-course priming study, Quémart et al. (2011) had shown that morphemes' form dimensions influence visual word recognition at $60 \mathrm{~ms}$ and $250 \mathrm{~ms}$, even though their semantic dimensions also influence morphological processing at $250 \mathrm{~ms}$. Based on these results, we used two prime durations: $60 \mathrm{~ms}$ (Experiment 1) and $250 \mathrm{~ms}$ (Experiment 2). Reasoning that the development of morphological representations is driven by morphemes' form dimensions, we predicted that the youngest readers would be deeply sensitive to the form overlap between morphologically related words in the earliest stages of morphological decomposition. As a consequence, we expected them to be hindered by the orthographic and phonological shifts in the base words in Experiment 1 (as evidenced by Schiff et al., 2008). By contrast, we expected the more advanced readers (i.e., fifth graders and adults) to activate more easily base words from their allomorphs, given that they would have had more opportunities to establish connections between these base words and their allomorphic 
variants. In Experiment 2, we expected all the participants (i.e., children and adults) to be influenced by the semantic overlap between morphologically related words. As a consequence, they should benefit from the morphological structure of the words, and process complex words faster than simple words independently of the form modifications to the base words.

\section{Experiment 1: 60-ms Prime Duration}

\section{Method}

Participants. Sixty-two French-speaking children (22 third graders, 20 fourth graders and 20 fifth graders) took part in this experiment. They were recruited from three different primary schools around the city of Lille (Northern France) and all had parental consent to participate in the study. The participants' chronological ages, reading ages (as assessed by the Alouette French reading test; Lefavrais, 1967), and nonverbal reasoning abilities (as measured by Raven's Progressive Matrices; Raven, Court, \& Raven, 1995) are summarized in Table 1.

An additional group of 15 students at the University of Lille was also recruited. They reported normal or corrected-to-normal vision, and no credit was given for participation.

(Insert Table 1 about here)

Materials and design. We selected 64 French words as targets from the Manulex Infra French lexical database (Peereman, Lété, \& Sprenger-Charolles, 2007), which provides the grade-level estimated surface frequency (per million words) and neighborhood size of child-directed printed words taken from school textbooks. These words were divided into four sets, each containing 16 items. Each set corresponded to one of the four priming conditions and each target in each condition was primed by a related and an unrelated word. 
The related primes could share four distinct relationships with the targets:

morphological relationship without any form shift in the base ${ }^{2}$ (M-Stable; e.g., nuageux [cloudy]-NUAGE [cloud], /nyazø/-/nyaz/); morphological relationship with a phonological shift in the base (M-Pshift; e.g., bergerie [sheepfold]-BERGER [shepherd], /ber3라i/-/brrze/, an equivalent in English would be natural-NATURE); morphological relationship with both a phonological and an orthographic shift in the base (M-OPshift; e.g., soigneux [careful]-SOIN [care], /swan $\emptyset /-/ s w \underline{\tilde{\varepsilon}} /$, an equivalent in English would be fifth-FIVE); and orthographic relationship (Orthographic control; e.g., fourmi [ant]-FOUR [oven]; an equivalent in English would be turnip-TURN).

Based on the statistics provided by Manulex Infra, the primes were matched for length, frequency and orthographic neighborhood (N-size) across all four priming conditions, $F \mathrm{~s}<1.18$. The targets were matched for frequency $(F<1)$, but could not be perfectly matched for length, $F(3,60)=2.35, p=.08$, as targets in the M-Stable condition tended to be longer than targets in the Orthographic condition $(p=.06)$. The N-size of the targets also depended on the condition, $F(3,60)=3.61, p=.02$, as targets in the M-Stable condition had significantly more neighbors than targets in the Orthographic condition $(p=.015)^{3}$. These characteristics are summarized in Table 2.

\footnotetext{
${ }^{2}$ The deletion of a silent $e$ was not regarded as a form modification here, as many French words end with a silent $e$, and this is very often replaced by another vowel (e.g., policepolicier) during the derivation process.

${ }^{3}$ We did not consider these lacks of matching as problematic since it went against our hypotheses according to which morphological primes should induce more priming than orthographic primes
} 
(Insert Table 2 about here)

Sixty-four unrelated word primes that had no form or semantic overlap with the targets were included in the experiment. They were matched to the related primes on frequency, length and $\mathrm{N}$-size $(F \mathrm{~s}<1)$. An additional set of 16 unrelated prime-target pairs was created to reduce the proportion of trials in which the target was related to the prime. In total, the participants saw 144 targets, 64 preceded by a related prime and 80 by an unrelated prime. A full list of the targets, related primes and unrelated primes is provided in the Appendix.

For the purpose of the lexical decision task, 144 pseudoword targets were included in the experimental material. Sixty-four pseudoword targets were preceded by a related prime, and 80 by an unrelated prime. Related targets were created by changing one or two letters in the related prime, whereas unrelated targets were created by changing one or two letters in an existing French word that was not included in the experiment.

The stimuli were divided into two experimental lists, such that a target word was preceded by a related prime in one list and by an unrelated prime in the other list. We used a within-participants design whereby participants saw each target word twice, once in the related condition and once in the unrelated condition. In order to limit the possible effect of repetition on lexical decisions, we administered the reading and nonverbal reasoning tests between the two experimental lists. In addition, the order of list presentation was entered as a factor in the analyses of variance (ANOVAs).

Procedure. The participants were tested individually in a quiet room in their school building (for children) or at the University (for adults). They were seated in front of a Dell Latitude 131L laptop screen and asked to decide as quickly and as accurately as possible 
whether the visual stimuli were real words ("p" key of the keyboard for right-handed participants) or made-up words (“q" key of the keyboard for right-handed participants ${ }^{4}$ ).

Stimulus presentation and data collection were controlled using E-Prime software (Schneider, Eschmann, \& Zuccolotto, 2002). The timing of the specific stimulus events in each lexical decision trial was as follows: (1) a fixation cross (+) displayed on the screen for $1000 \mathrm{~ms}$ (and also served as Inter-Trial Interval); (2) a forward mask (\#\#\#\#) displayed for $800 \mathrm{~ms}$; (3) a lowercase prime word displayed for $60 \mathrm{~ms}$; immediately followed by (4) an uppercase target word or pseudoword (displayed until response or for a maximum of 5000 $\mathrm{ms})$.

The experiment took place in a single session (lasting about 15 minutes), consisting of one block of 10 practice trials followed by two blocks of 144 experimental trials (Lists 1 and 2). The order of list presentation was counterbalanced and the order of presentation of the items within each list was randomized.

\section{Data treatment}

Reaction times (RTs) and error rates were collected, and are set out in Table 3. However, because of ceiling effects on the accuracy measures, statistical analyses were only carried out on RTs. Latency data for incorrect responses and datapoints greater than three standard deviations above the mean $(1.89 \%$ of the data for word targets) were excluded from the RT analysis. Four items were excluded from the data analysis because of high error rates: bout [piece]: $19.09 \%$; odeur [smell]: 16.80\%; plomb [lead]: 19.83\%; and ras [short]: 22.14\%. Two participants in Grade 3 were excluded, as their error rates were more than three standard deviations above the mean. Finally, RTs were log-transformed to correct a rightward skew (Ratcliff, 1993).

\footnotetext{
${ }^{4}$ Left-handed participants did the opposite.
} 
Separate analyses were conducted in adults and in children. In both groups, ANOVAs were performed on log-transformed RTs for correct responses with condition (M-Stable; MPshift; M-OPshift; Orthographic), priming (related, unrelated) and order of list presentation $(1,2)$ as within-participants variables. In children, grade $(3,4,5)$ was treated as an additional between-participants variable.

(Insert Table 3 about here)

\section{Results in adults}

The main effect of priming was significant, $F(1,14)=36.59, p<.001, \eta_{p}^{2}=.72$, and significantly interacted with condition, $F(3,42)=3.31, p=.019, \eta_{p}^{2}=.21$. The interaction between priming, condition and order of list presentation was not significant $(F<1)$ and for this reason we will focus on the Priming x Condition interaction.

Planned comparisons showed that related primes speeded up lexical decisions compared to unrelated primes in the three morphological conditions (M-stable: $F(1,14)=$ 39.99, $p<.001, \eta_{p}^{2}=.74$, M-Pshift: $F(1,14)=10.17, p=.007, \eta_{p}^{2}=.42$ and M-OPshift: $\left.F(1,14)=10.10, p=.007, \eta_{p}^{2}=.42\right)$ but not in the orthographic control condition, $F(1,14)=$ $2.72, p=.12, \eta_{p}^{2}=.16$. The amount of priming did not differ significantly between the three morphological conditions, $F(2,28)=1.57, p=.23, \eta_{p}^{2}=.10$.

\section{Results in children}

As we were specifically interested in the main effect of grade, as well as in the interaction effects between grade, condition and priming, we only report the results of these analyses. The order of list presentation did not interact significantly with the condition and priming factors $(F<1)$ and is not discussed further. 
ANOVAs revealed a main effect of grade, $F(2,57)=18.86, p<.001, \eta^{2}{ }_{\mathrm{p}}=.40$. Post hoc analyses indicated that mean RTs were slower in Grade $3(M=1519 \mathrm{~ms})$ than in Grades 4 $(M=1165 \mathrm{~ms})$ or $5(M=1009 \mathrm{~ms})$. However, there was no difference in RTs between Grades 4 and 5. The main effect of priming was significant, $F(1,57)=7.11, p=.009, \eta_{\mathrm{p}}^{2}=.12$, and interacted significantly with condition, $F(3,171)=4.54, p=.005, \eta_{\mathrm{p}}^{2}=.07$. However, the interaction between grade, priming and condition did not reach significance.

Planned comparisons conducted on the Priming x Condition interaction revealed that RTs were faster when targets were preceded by related primes in the morphological condition without any modification to the base, $F(1,57)=16.01, p<.001, \eta_{\mathrm{p}}^{2}=.21$, but priming effects were not significant in the other three conditions, $F \mathrm{~s}<1.7$.

\section{Discussion}

The aim of Experiment 1 was to investigate whether phonological and orthographic shifts in a base word interfere with the very early stages of morphological processing in developing readers and in skilled readers. Different patterns of priming were observed according to reading expertise: While priming effects were significant in the three morphological conditions in adults, they were only significant when there was an exact orthographic and phonological match between the standalone base and the base embedded in a derived form in children.

The present results indicate that morphological decomposition is both rapid and automatic as early as Grade 3, as reported in previous studies (Beyersmann et al., 2012; Quémart et al., 2011; Schiff et al., 2008). Most importantly with respect to the aim of the present study, the influence of orthographic and/or phonological shifts to the base on target recognition changed as a function of reading expertise. Children's ability to process morphemic units within complex words depended on the possibility of extracting a base word 
that is orthographically and phonologically similar to the standalone base. By contrast, adult readers were able to capitalize on allomorph primes to process targets.

The influence of form shifts in the base word has already been observed in Englishspeaking developing readers with a naming task (Carlisle, 2000; Deacon et al., 2010; Mann \& Singson, 2003) and a lexical decision task (Carlisle \& Stone, 2005). Using the masked priming paradigm, Schiff et al. (2008) also showed that word naming by Hebrew-speaking third and seventh graders is not significantly influenced by the presence of a prime if the form overlap between the two successive stimuli is incomplete. Our results for the French language are in line with these findings, indicating that developing readers rely heavily on the form dimensions of morphemes when breaking morphologically complex words down into smaller components. Patterns of priming in adults are also in line with previous results reported in English, and, at the same time, extend them to derivational primes (Crepaldi et al., 2010, used inflectional primes) and to larger form shifts as compared to McCormick et al. (2008).

This result has two critical implications in developing readers. First, the presence of a suffix at the end of words is not the only factor to trigger morphological decomposition. They also need to locate a base word that is intact (i.e., identical in form to the standalone base). The importance of base words in morphological decomposition has already been highlighted by Quémart, Casalis, and Duncan (2012), as well as by Carlisle and Stone (2003). The current study adds to this body of research by showing that the influence of the base occurs at a very early stage in the time course of visual word recognition, and is grounded on the extraction of the form properties of the base word. Second, a morpho-orthographic overlap between prime and target is not sufficient to trigger morphological priming, as no significant priming was observed in the M-Pshift condition. Phonological alterations to the base prevent complex words from being broken down, even if the base word does not undergo any orthographic shifts in its derived form. This is a striking result, as phonological activation has been shown 
to occur after orthographic activation in the time course of visual word recognition in skilled readers (Ferrand \& Grainger, 1993; Grainger, Kiyonaga, \& Holcomb, 2006). In the present study, the influence of phonological modifications was observed as early as $60 \mathrm{~ms}$, indicating that developing readers may activate phonological codes even at this early stage in visual word recognition. Rapid and automatic phonological activation has already been observed in the form of pseudohomophone priming effects at $30 \mathrm{~ms}$ and $60 \mathrm{~ms}$ between Grades 2 and 6 (Booth, Perfetti, \& MacWhinney, 1999). In the present study, the lack of phonological correspondence between primes and targets may have prevented developing readers from benefiting from the prime when processing the target. Implications of these results will be addressed in the General Discussion.

\section{Experiment 2: 250-ms Prime Duration}

In order to examine whether developing readers are still influenced by form shifts in the base word at a later stage in the time course of visual word recognition, we conducted another experiment with third-, fourth- and fifth-grade readers as well as with adults. In this experiment, we used exactly the same procedure as in Experiment 1, except that we increased the prime duration to $250 \mathrm{~ms}$. As developing readers have been shown to be influenced by the semantic dimensions of morphemes at $250 \mathrm{~ms}$ (Quémart et al., 2011), we postulated that the semantic overlap between morphologically related words prevail in morphological decomposition. As a consequence, we expected to observe significant priming effects in both groups, and in all three morphological conditions (M-Stable, M-Pshift and M-OPshift).

\section{Method}

Participants. A new group of 64 French-speaking children (20 third graders, 22 fourth graders and 22 fifth graders) were recruited from three different primary schools around the city of Lille (Northern France). Their mean chronological age, reading age and nonverbal reasoning abilities are summarized in Table 4. 
Thirteen students at the University of Lille and native speakers of French also participated in the experiment. They reported normal or corrected-to-normal vision, and no credit was given for participation.

(Insert Table 4 about here)

Materials and design. The materials and design were the same as in Experiment 1.

Procedure. The procedure was almost the same as in Experiment 1, except that the prime duration was $250 \mathrm{~ms}$ and the presence of a prime was mentioned to the participants.

\section{Data treatment}

The mean RTs and error rates are set out in Table 5. We used the same trimming procedure as in Experiment 1. All the trials leading to incorrect responses and datapoints more than three standard deviations above the mean (1.98\% of the data for word targets) were excluded from the RT analysis. The same four items were excluded from the data analysis as in Experiment 1 (i.e., bout [piece]: 19.51\%; odeur [smell]: 10.41\%; plomb [lead]: 18.62\%; ras [short]: $30.05 \%$ ). One participant in Grade 3 was excluded because of error rates of more than three standard deviations above the mean. As in Experiment 1, RTs were log-transformed to correct a rightward skew of data distribution (Ratcliff, 1993).

(Insert Table 5 about here)

\section{Results in adults}

The main effect of priming was significant, $F(1,12)=26.45, p<.001, \eta_{p}^{2}=.69$, and significantly interacted with the condition, $F(3,36)=3.91, p=.016, \eta_{p}^{2}=.25$. The interaction 
between priming, condition and order of list presentation was not significant $(F(3,36)=1.14$, $\left.p=.35, \eta_{p}^{2}=.09\right)$ and will not be discussed further.

Planned comparisons showed faster RTs when targets were preceded by morphologically related primes (M-stable: $F(1,12)=11.43, p=.005, \eta^{2}=.49$; M-Pshift: $F(1,12)=18.09, p=.001, \eta_{p}^{2}=.60 ;$ M-OPshift: $\left.F(1,12)=16.93, p=.001, \eta_{p}^{2}=.59\right)$, but not when they were preceded by orthographic control primes, $F(1,12)=1.56, p=.24, \eta_{p}^{2}=.12$. The amount of priming was not different amongst the three morphological conditions, $F(2$, 24) $=1.46, p=.25, \eta_{p}^{2}=.11$.

\section{Results in children}

Overall, the main effect of grade was significant, $F(2,60)=12.60, p<.001, \eta_{\mathrm{p}}^{2}=.30$. Post hoc analyses showed that the mean RTs of third graders $(M=1349 \mathrm{~ms})$ were longer than those of fourth graders $(M=1131 \mathrm{~ms})$ and fifth graders $(M=1043 \mathrm{~ms})$. However, the mean RTs of fourth and fifth graders did not differ significantly from each other. There was a main effect of priming, $F(1,60)=51.70, p<.001, \eta_{\mathrm{p}}^{2}=.46$, which interacted significantly with condition, $F(3,180)=2.90, p=.037, \eta_{\mathrm{p}}^{2}=.05$. However, the three-way interaction between grade, priming and condition was not significant $(F<1)$. Finally, the order of list presentation did not interact significantly with the condition and priming factors $(F<1)$.

Planned comparisons were performed to explore the Priming x Condition interaction. In the M-Stable condition, RTs were faster when targets were preceded by related primes than by unrelated primes, $F(1,60)=6.80, p=.011, \eta_{\mathrm{p}}^{2}=.10$. Significant priming effects were also found in the M-Pshift condition, $F(1,60)=19.17, p<.001, \eta_{\mathrm{p}}^{2}=.24$, and in the M-OPshift condition, $F(1,60)=16.58, p<.001, \eta_{\mathrm{p}}^{2}=.21$. No significant priming effect was found in the orthographic control condition, $F<1$. 
Finally, we examined whether the degree of morphological priming depended on the condition. The ANOVA indicated that the extent of the priming effects did not differ across the three morphological conditions, $F<1$.

\section{Discussion}

The goal of Experiment 2 was to investigate the influence of form shifts in the base word on morphological decomposition by French third, fourth and fifth graders and adults, with a longer prime duration than in Experiment 1 (i.e., $250 \mathrm{~ms}$ ). In both groups (children and adults), significant priming effects were observed in all three morphological conditions (i.e., M-Stable, M-Pshift, M-OPshift) but not in the orthographic control condition. These results confirm that developing readers benefit from a morphological overlap between prime and target, and indicate that the form overlap between morphologically related primes and targets is not as crucial as it was at $60 \mathrm{~ms}$ to induce priming. The results of Experiment 1 and Experiment 2 will be jointly analyzed in the General Discussion.

\section{General Discussion}

There is growing evidence that developing readers are capable of breaking morphologically complex words down into smaller components during visual word recognition as early as age 7 years (Carlisle \& Stone, 2005; Laxon, Rickard, \& Coltheart, 1992). However, morphological derivation often involves slight orthographic and phonological modifications to the base word, which may impinge on the relationship between a base and its derived form. In the present study, we therefore used the priming paradigm to examine whether French elementary school children (compared to skilled readers) require a complete phonological and orthographic overlap between morphologically related words in order to process the form properties of their constituent morphemes.

The main results can be summarized as follows. In developing readers, when primes were displayed for $60 \mathrm{~ms}$ (Experiment 1), they only facilitated the processing of a 
morphologically related target if there was an exact phonological and orthographic overlap between prime and target. However, when primes were displayed for $250 \mathrm{~ms}$ (Experiment 2), their facilitating effect on target processing was observed whenever they were morphologically related, independently of any form modifications to the base. These priming effects were observed for each of Grades 3, 4 and 5. In contrast, priming effects were significant in the three morphological conditions in adults, whatever the prime duration (Experiment 1 and Experiment 2).

Three results were consistently observed in both experiments in each group. First, priming effects were always significant in the morphological condition with no modification of the base, as already evidenced in several studies in adults (Amenta \& Crepaldi, 2012) and in children (Beyersmann et al., 2012; Quémart et al., 2011). Second, priming effects were never significant in the orthographic control condition, reinforcing the idea that morphological priming effects cannot be attributed to a simple orthographic overlap between primes and targets. Third, priming effects never differed from each other in the two morphological conditions with form modification, even when we collapse the results of both experiments $(F(1,138)=1.8, p=.18)$. Children are not more hindered when phonological shift is associated to orthographic shift than when it is not. The phonological overlap between morphologically related words thus appears central when decomposing morphologically complex words. Schreuder and Baayen (1995) already proposed that the phonological stability of the base in the derived form is critical to detect morphological relationships between words. The present results are consistent with this conception, and argue in favor of an early influence of phonological codes during visual word recognition in children.

\section{Early Influence of Form Shifts in the Base Word}

The novel contribution of the present study concerns the processing of the form dimensions of morphemes by developing readers in relation to the time course of visual word 
recognition. In a previous study, Quémart et al. (2011) had shown that the semantic dimensions of morphemes did not significantly influence the first steps of morphological processing. This result was taken to suggest that morphological decomposition is initially driven by morphemes' form dimensions. The present study extends this finding by demonstrating that the processing of these form properties requires an exact phonological and orthographic match between the base and its derived form in developing readers during the earliest stages of word recognition. These results contrast with those observed in skilled readers, who are not significantly hindered by the form modifications of the base word when processing allomorphs (see also Crepaldi et al., 2010; McCormick et al., 2008).

The discrepancy between the different priming patterns observed in children and in adults certainly results from differences in the time course of morpho-orthographic and morpho-semantic procedures in the two groups. Although many studies have shown that these routes influence word recognition successively in skilled readers (Longtin et al., 2003; Rastle, Davis, Marslen-Wilson, \& Tyler, 2000), growing evidence has emerged recently in favor of their simultaneous influence very early in the time course of word recognition (Diependaele et al., 2005, 2009; Feldman, O’Connor, \& del Prado Martín, 2009; Järvikivi \& Pyykkönen, 2011; Marelli, Amenta, Morone, \& Crepaldi, 2013). As explained by Diependaele et al. (2009), the morpho-orthographic and morpho-semantic procedures are activated in parallel and connected via feedback connections. When they are both activated, they "resonate" with each other, leading to greater priming effects when words are truly morphologically related than when they are not (i.e., pseudoderivation).

The way in which these two procedures code orthographic information was recently described by Grainger and Ziegler (2011; see also Grainger, Lété, Bertand, Dufau, \& Ziegler, 2012). According to their dual-route approach to orthographic processing, skilled orthographic processing is characterized by the parallel activation of two distinct processing 
routes that differ with respect to the grain size of the orthographic code activated: the finegrained route, which codes absolute grapheme position (e.g., CH.A.I.R), and the coarsegrained route, which allows rapid access to semantic representations at the cost of precise grapheme position coding (e.g., C-A; C-I; C-R; H-A, etc.). Interestingly, the dual-route approach proposes that the morpho-orthographic and morpho-semantic procedures proposed by Diependaele et al. $(2005 ; 2009)$ are characterized by fine-grained and coarse-grained processing of the orthography, respectively.

The ability of skilled readers to use allomorphic primes to process targets may reflect the parallel activation of the fine-grained morpho-orthographic procedure and the coarsegrained morpho-semantic procedure. Even though the morpho-orthographic procedure fails to activate the appropriate base word because of form shifts of the base, the morpho-semantic procedure activated in parallel makes it possible to resolve the lack of form overlap between morphologically related words because these allomorphs are connected to each other within the lexicon. Top-down activation spreads from the morpho-semantic to the lexical level, increasing the activation level of the members of the morphological family, and therefore leading to priming effects.

In developing readers, the picture is different. As explained in the Introduction, their sensitivity to the semantic dimensions of morphemes is perceptible later than that of their form dimensions across the time course of word recognition (Quémart et al., 2011). Even if, as with adults, both procedures are activated in parallel, we can expect one procedure to take more time than the other one to significantly influence lexical access. Children's change in sensitivity to form shifts across the time course of word recognition may therefore result from a different efficiency of the morpho-orthographic and the morpho-semantic procedures. The first one is rapidly efficient for dealing with morphemes' form properties, provided that there is an exact form overlap between morphologically related words. The lack of form overlap 
between primes and targets in the two morphological shift conditions might thus have prevented primes to pre-activate targets. The second one is devoted to the processing of morphemes' semantic properties, and, as it is coarse-grained, it is activated even if there are phonological or orthographic shifts in the base word. However, the impact of the morphosemantic procedure is visible later in the time course of word recognition (Quémart et al., 2011), which explains why developing readers are not immediately able to deal with form modifications of the base.

This interpretation might appear counterintuitive since the coarse-grained procedure is supposed to allow fast access to semantics, at the expense of a precise letter position coding. However, priming effects attributed to the influence of the morpho-semantic procedure are the consequence of bottom-up and top-down activations (Diependaele et al., 2009). Since the spread of information along the different levels of processing is generally slower in children than in adults, the delayed influence of this level of processing in children might result from the necessity of the coarse-grained morpho-semantic procedure to activate several levels of processing. Another potentially slowing factor of the morpho-semantic procedure is related to children's morphological awareness. The development of the morpho-semantic procedure requires children to establish connections between members of the same morphological family, probably by using form-meaning regularities (Rastle \& Davis, 2008; Verhoeven \& Perfetti, 2011). However, it is more difficult to detect relationships between allomorphs than between words with no modification of the base in the derived form (Gonnerman, Seidenberg, \& Andersen, 2007). We can suppose that developing readers have not yet established enough connections between these words to benefit quickly from their morphological relationship. If these connections have not been sufficiently reinforced, the influence of the feedback connections between the morpho-semantic and the lexical level will be delayed, as observed in the present study. 


\section{Reconciling the Effects of Form Shifts Highlighted in Naming Versus Priming Experiments}

Our results also raise the question of task influence when assessing the role of morphology in visual word recognition. Naming tasks have consistently shown developing readers to be hindered by form modifications to the base word when reading (Carlisle, 2000; Deacon, Whalen, \& Kirby, 2011; Mann \& Singson, 2003). However, the children in the present study were only affected by form modifications at the very beginning of the word recognition process.

One possible explanation is that naming can be achieved without necessarily activating lexical representations. The impact of form modifications on word naming may thus be the direct consequence of activating sublexical representations during naming. As these representations are thought to be particularly sensitive to letter position, they negatively influence children's naming of shift words. The impact of phonological and orthographic modifications on lexical decisions is less obvious. For example, Carlisle and Stone (2005; see also Carlisle, Stone, \& Katz, 2001) have shown that form modifications have less of an impact when deciding whether or not an item is a word than when naming a word. The influence of form shifts has also been found to be less pronounced in a fragment completion task (Feldman et al., 2002), which is also assumed to involve lexical activation. The different results obtained in naming and lexical decision tasks may thus arise from the type of paradigm used, and extreme caution therefore needs to be exercised in order to select the most appropriate task for assessing reading abilities in developing readers. Control stimuli should also be selected with care. Several studies have indicated that the presence of embedded morphemes facilitates lexical access and naming, even if the words are not morphologically complex (Duncan, Gray, Quémart, \& Casalis, 2010; Quémart et al., 2012; Traficante, Marcolini, Luci, Zoccolotti, \& Burani, 2011), so it is important to compare the processing of 
morphologically complex words with that of monomorphemic words that do not contain embedded morphemes.

The main limitation of the present study concerns the considerable variability in RTs in both experiments. It may indeed have prevented us from picking up significant differences between conditions and/or between grades. A larger group of participants might help to overcome this problem in future studies.

To conclude, the present study provides information regarding the development of morphological representations, showing that they are constructed at two distinct levels: morpho-orthographic and morpho-semantic. Both form and semantic information needs to be associated with morphological representations, for the reader to perform morphological decomposition efficiently and to access lexical representations more easily. 


\section{References}

Amenta, S., \& Crepaldi, D. (2012). Morphological processing as we know it: An analytical review of morphological effects in visual word identification. Frontiers in Psychology, 3, 1-12. doi:10.3389/fpsyg.2012.00232

Beyersmann, E., Castles, A., \& Coltheart, M. (2012). Morphological processing during visual word recognition in developing readers: Evidence from masked priming. Quarterly Journal of Experimental Psychology, 65, 1306-1326.

doi:10.1080/17470218.2012.656661

Booth, J. R., Perfetti, C. A., \& MacWhinney, B. (1999). Quick, automatic, and general activation of orthographic and phonological representations in young readers. Developmental Psychology, 35, 3-19.

Carlisle, J. F. (2000). Awareness of the structure and meaning of morphologically complex words: Impact on reading. Reading and Writing: An Interdisciplinary Journal, 12, 169-190. doi:10.1023/A:1008131926604

Carlisle, J. F., \& Stone, C. A. (2003). The effects of morphological structure on children's reading of derived words in English. In E. Assink \& D. Sandra (Eds.), Reading complex words: Cross-language studies (pp. 27-52). New-York: Kluwer Academic.

Carlisle, J. F., \& Stone, C. A. (2005). Exploring the role of morphemes in word reading. Reading Research Quarterly, 40, 428-449. doi: 10.1598/RRQ.40.4.3

Carlisle, J. F., Stone, C., \& Katz, L. (2001). The effects of phonological transparency on reading derived words. Annals of Dyslexia, 51, 249-274. doi:10.1007/s11881-001$0013-2$

Crepaldi, D., Rastle, K., Coltheart, M. \& Nickels, L. (2010). 'Fell' primes 'fall' but does 'bell' prime 'ball'? Masked priming with irregularly-inflected primes. Journal of Memory and Language, 63, 83-99. doi:http://dx.doi.org/10.1016/j.jml.2010.03.002 
Deacon, S. H., Campbell, E., Tamminga, M., \& Kirby, J. R. (2010). Seeing the harm in harmed and harmful: Morphological processing by children in Grades 4, 6, and 8 . Applied Psycholinguistics, 31, 759-775. doi:10.1017/S0142716410000238

Deacon, S. H., Whalen, R., \& Kirby, J. R. (2011). Do children see the danger in dangerous? Grade 4, 6, and 8 children's reading of morphologically complex words. Applied Psycholinguistics, 32, 467-481. doi:10.1017/S0142716411000166

Diependaele, K., Sandra, D., \& Grainger, J. (2005). Masked cross-modal morphological priming: Unravelling morpho-orthographic and morpho-semantic influences in early word recognition. Language \& Cognitive Processes, 20, 75-114. doi:10.1080/01690960444000197

Diependaele, K., Sandra, D., \& Grainger, J. (2009). Semantic transparency and masked morphological priming: The case of prefixed words. Memory and Cognition, 37, 895908. doi:10.3758/MC.37.6.895

Duncan, L., Gray, E., Quémart, P. \& Casalis, S. (2010). Do good and poor readers make use of morphemic structure in English word recognition? Journal of Portuguese Linguistics, 9/10, 143-160.

Feldman, L. B., O’Connor, P., \& del Prado Martín, F. (2009). Early morphological processing is morphosemantic and not simply morpho-orthographic: A violation of form-thenmeaning accounts of word recognition. Psychonomic Bulletin \& Review, 16, 684-691. doi:10.3758/pbr.16.4.684

Feldman, L. B., Rueckl, J., DiLiberto, K., Pastizzo, M. J., \& Vellutino, F. R. (2002). Morphological analysis by child readers as revealed by the fragment completion task. Psychonomic Bulletin \& Review, 9, 529-535. doi:10.3758/BF03196309 
Feldman, L. B., Soltano, E. G., Pastizzo, M. J., \& Francis, S. E. (2004). What do graded effects of semantic transparency reveal about morphological processing? Brain and Language, 90, 17-30. doi:10.1016/S0093-934X(03)00416-4

Ferrand, L., \& Grainger, J. (1993). The time course of orthographic and phonological code activation in the early phases of visual word recognition. Bulletin of the Psychonomic Society, 31, 119-122.

Gonnerman, L.M., Seidenberg, M.S., \& Andersen, E.S. (2007). Graded semantic and phonological similarity effects in priming: Evidence for a distributed connectionist approach to morphology. Journal of Experimental Psychology: General, 136, 323345. doi: 10.1037/0096-3445.136.2.323

Gough, P. B., \& Tunmer, W. E. (1986). Decoding, reading, and reading disability. Remedial and Special Education, 7, 6-10. doi:10.1177/074193258600700104

Grainger, J., Kiyonaga, K., \& Holcomb, P. J. (2006). The time course of orthographic and phonological code activation. Psychological Science, 17, 1021-1026. doi:10.1111/j.1467-9280.2006.01821.x

Grainger, J., Lété, B., Bertand, D., Dufau, S., \& Ziegler, J. C. (2012). Evidence for multiple routes in learning to read. Cognition, 123, 280-292. doi:http://dx.doi.org/10.1016/j.cognition.2012.01.003

Grainger, J., \& Ziegler, J. C. (2011). A dual-route approach to orthographic processing. Frontiers in Psychology, 2, 1-13. doi:10.3389/fpsyg.2011.00054

Järvikivi, J., \& Pyykkönen, P. (2011). Sub- and supralexical information in early phases of lexical access. Frontiers in Psychology, 2, 1-12. doi:10.3389/fpsyg.2011.00282

Kirby, J. R., Deacon, S. H., Bowers, P., Izenberg, L., Wade-Woolley, L., \& Parrila, R. K. (2012). Children's morphological awareness and reading ability. Reading and Writing, 25, 389-410. doi:10.1007/s11145-010-9276-5 
Laxon, V., Rickard, M., \& Coltheart, V. (1992). Children read affixed words and non-words. British Journal of Psychology, 83, 407-423. doi :10.1111/j.2044-8295.1992.tb02450.x

Lefavrais, P. (1967). Test de l'Alouette [The Alouette test]. Paris: Editions du Centre de Psychologie Appliquée.

Longtin, C.-M., Segui, J., \& Hallé, P. A. (2003). Morphological priming without morphological relationship. Language \& Cognitive Processes, 18, 313. doi:10.1080/01690960244000036.

Mann, V., \& Singson, M. (2003). Linking morphological knowledge to English decoding ability: Large effects of little suffixes. In E. M. H. Assink \& D. Sandra (Eds.), Reading complex words: Cross-language studies (pp. 1-26). New York: Kluwer Academic.

Marelli, M., Amenta, S., Morone, E. A., \& Crepaldi, D. (2013). Meaning is in the beholder's eye: Morpho-semantic effects in masked priming. Psychonomic Bulletin \& Review, 20, 534-541. doi:10.3758/s13423-012-0363-2

Marslen-Wilson, W. D., Bozic, M., \& Randall, B. (2008). Early decomposition in visual word recognition: Dissociating morphology, form, and meaning. Language \& Cognitive Processes, 23, 394-421. doi:10.1080/01690960701588004

Marslen-Wilson, W. D., Tyler, L. K., Waksler, R., \& Older, L. (1994). Morphology and meaning in the English mental lexicon. Psychological Review, 101, 3-33. doi:10.1037/0033-295X.101.1.3

McCormick, S. F., Rastle, K., \& Davis, M. H. (2008). Is there a 'fete' in 'fetish'? Effects of orthographic opacity on morpho-orthographic segmentation in visual word recognition. Journal of Memory and Language, 58, 307-326.

doi:10.3758/PBR.16.4.684 
Nation, K., \& Snowling, M. J. (2004). Beyond phonological skills: Broader language skills contribute to the development of reading. Journal of Research in Reading, 27, 342356. doi:10.1111/j.1467-9817.2004.00238.x

Peereman, R., Lété, B., \& Sprenger-Charolles, L. (2007). Manulex-infra: Distributional characteristics of grapheme-phoneme mappings, and infralexical and lexical units in child-directed written material. Behavior Research Methods, 39, 579-589. doi:10.3758/BF03193029

Quémart, P., Casalis, S., \& Colé, P. (2011). The role of form and meaning in the processing of written morphology: A priming study in French developing readers. Journal of Experimental Child Psychology, 109, 478-496. doi:10.1016/j.jecp.2011.02.008

Quémart, P., Casalis, S., \& Duncan, L. G. (2012). Exploring the role of bases and suffixes when reading familiar and unfamiliar words: Evidence From French young readers. Scientific Studies of Reading, 16, 424-442. doi:10.1080/10888438.2011.584333

Rastle, K., \& Davis, M. H. (2008). Morphological decomposition based on the analysis of orthography. Language \& Cognitive Processes, 23, 942-971. doi:http://dx.doi.org/10.1080/01690960802069730

Rastle, K., Davis, M. H., Marslen-Wilson, W.D., \& Tyler, L. K. (2000). Morphological and semantic effects in visual word recognition: A time-course study. Language \& Cognitive Processes, 15, 507-537. doi:10.1080/01690960050119689

Rastle, K., Davis, M. H., \& New, B. (2004). The broth in my brother's brothel: Morphoorthographic segmentation in visual word recognition. Psychonomic Bulletin \& Review, 11, 1090-1098. doi:10.3758/BF03196742

Ratcliff, R. (1993). Methods for dealing with reaction time outliers. Psychological Bulletin, 114, 510-532. doi:10.1037/0033-2909.114.3.510 
Raven, J. C., Court, J. H., \& Raven, J. (1995). Raven manual: Coloured progressive matrices. Oxford: Oxford Psychologists Press.

Schiff, R., Raveh, M., \& Kahta, S. (2008). The developing mental lexicon: Evidence from morphological priming of irregular Hebrew forms. Reading and Writing, 21, 719-743. doi:10.1007/s11145-007-9088-4

Schneider, W., Eschmann, A., \& Zuccolotto, A. (2002). E-Prime reference guide. Pittsburgh, PA: Psychology Software Tools.

Schreuder, R., \& Baayen, R. H. (1995). Modeling morphological processing. In L. B. Feldman (Ed.), Morphological aspects of language processing (pp. 131-154). Hillsdale, NJ: Erlbaum.

Traficante, D., Marcolini, S., Luci, A., Zoccolotti, P., \& Burani, C. (2011). How do roots and suffixes influence reading of pseudowords: A study of young Italian readers with and without dyslexia. Language \& Cognitive Processes, 26, 777-793. doi:10.1080/01690965.2010.496553

Verhoeven, L., \& Perfetti, C. A. (2011). Morphological processing in reading acquisition: A cross-linguistic perspective. Applied Psycholinguistics, 32, 457-466. doi:10.1017/S0142716411000154 
Table 1

Experiment 1: Children's Mean Chronological Age (CA), Reading Age (RA) and nonverbal reasoning abilities (Raven) as a function of the grade (standard deviations are shown in parentheses)

\begin{tabular}{llll}
\hline & CA (year; month) & RA (year; month) & Raven (raw score) \\
\hline Grade 3 $(n=22)$ & $8 ; 6(4$ months $)$ & $8 ; 4(12$ months $)$ & $30.20(3.83)$ \\
Grade $4(n=20)$ & $9 ; 7(5$ months $)$ & $9 ; 0(15$ months $)$ & $32.4(3.53)$ \\
Grade 5 $(n=20)$ & $10 ; 10(4$ months $)$ & $11 ; 3(10$ months $)$ & $33.22(2.18)$ \\
\hline
\end{tabular}


Table 2

Characteristics of the word items in Experiments 1 and 2

\begin{tabular}{lllll}
\hline & M-Stable & M-Pshift & M-OPshift & Orthographic \\
\hline Prime length & $7.88(0.96)$ & $7.88(0.81)$ & $7.56(0.81)$ & $7.63(1.02)$ \\
Target length & $5.44(0.96)$ & $4.94(1.13)$ & $5.13(0.89)$ & $4.56(0.51)$ \\
\hline Prime frequency & $22.04(24.53)$ & $18.15(24.30)$ & $21.36(15.79)$ & $20.93(14.83)$ \\
Target frequency & $103.69(65.19)$ & $102.46(109.87)$ & $100.43(53.82)$ & $97.97(89.90)$ \\
\hline Prime N-size & $0.38(0.81)$ & $0.69(0.95)$ & $0.38(0.62)$ & $1.13(1.78)$ \\
Target N-size & $1.94(2.52)$ & $3.94(2.73)$ & $3.00(2.05)$ & $5.81(1.78)$
\end{tabular}

Note. Length = mean number of letters; frequency = mean number of occurrences per million according to Manulex Infra database (Peereman et al., 2007); N-size = mean neighbourhood size. Standard deviations are shown in parentheses. 
Table 3

Experiment 1 (60-ms prime duration): Mean reaction times (RT in $\mathrm{ms}$ ), error percentages (Err \%) and priming effects (unrelated - related priming) as a function of priming, condition and group (standard deviations are shown in parentheses)

\begin{tabular}{|c|c|c|c|c|c|c|c|c|c|c|c|}
\hline \multirow{3}{*}{ 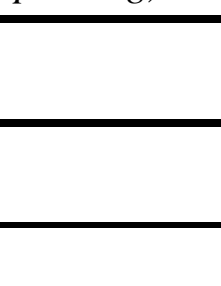 } & \multirow{3}{*}{ - } & \multicolumn{2}{|c|}{ Adults } & \multicolumn{8}{|c|}{ Children } \\
\hline & & \multirow[b]{2}{*}{ RT } & \multirow[b]{2}{*}{ Err \% } & \multicolumn{2}{|c|}{ Overall } & \multicolumn{2}{|c|}{ Grade 3} & \multicolumn{2}{|c|}{ Grade 4} & \multicolumn{2}{|c|}{ Grade 5} \\
\hline & & & & RT & Err \% & RT & Err \% & $\mathrm{RT}$ & Err \% & $\mathrm{RT}$ & Err \% \\
\hline \multirow[t]{3}{*}{ M-Stable } & Related & $\begin{array}{l}567 \\
(50)\end{array}$ & $\begin{array}{l}0.88 \\
(2.34)\end{array}$ & $\begin{array}{l}1140 \\
(294)\end{array}$ & $\begin{array}{l}4.90 \\
(6.30)\end{array}$ & $\begin{array}{l}1381 \\
(322)\end{array}$ & $\begin{array}{l}4.90 \\
(5.77)\end{array}$ & $\begin{array}{l}1088 \\
(185)\end{array}$ & $\begin{array}{l}6.16 \\
(7.83)\end{array}$ & $\begin{array}{l}952 \\
(172)\end{array}$ & $\begin{array}{l}3.65 \\
(5.05)\end{array}$ \\
\hline & Unrelated & $\begin{array}{l}615 \\
(63)\end{array}$ & $\begin{array}{l}2.22 \\
(4.82)\end{array}$ & $\begin{array}{l}1215 \\
(333)\end{array}$ & $\begin{array}{l}5.26 \\
(5.20)\end{array}$ & $\begin{array}{l}1470 \\
(376)\end{array}$ & $\begin{array}{l}7.04 \\
(5.89)\end{array}$ & $\begin{array}{l}1145 \\
(239)\end{array}$ & $\begin{array}{l}6.46 \\
(4.99)\end{array}$ & $\begin{array}{l}1031 \\
(194)\end{array}$ & $\begin{array}{l}2.29 \\
(3.21)\end{array}$ \\
\hline & Priming & 48 & 1.34 & 75 & 0.36 & 89 & 2.14 & 57 & 0.30 & 79 & -1.35 \\
\hline \multirow[t]{3}{*}{ M-PShift } & Related & $\begin{array}{l}590 \\
(78)\end{array}$ & $\begin{array}{l}0.88 \\
(2.34)\end{array}$ & $\begin{array}{l}1202 \\
(340)\end{array}$ & $\begin{array}{l}7.29 \\
(7.82)\end{array}$ & $\begin{array}{l}1457 \\
(395)\end{array}$ & $\begin{array}{l}9.20 \\
(8.85)\end{array}$ & $\begin{array}{l}1115 \\
(201)\end{array}$ & $\begin{array}{l}9.09 \\
(8.44)\end{array}$ & $\begin{array}{l}1032 \\
(235)\end{array}$ & $\begin{array}{l}3.57 \\
(4.34)\end{array}$ \\
\hline & Unrelated & $\begin{array}{l}620 \\
(57)\end{array}$ & $\begin{array}{l}3.56 \\
(4.95)\end{array}$ & $\begin{array}{l}1179 \\
(317)\end{array}$ & $\begin{array}{l}8.31 \\
(8.90)\end{array}$ & $\begin{array}{l}1453 \\
(352)\end{array}$ & $\begin{array}{l}9.49 \\
(9.36)\end{array}$ & $\begin{array}{l}1073 \\
(184)\end{array}$ & $\begin{array}{l}13.24 \\
(7.99)\end{array}$ & $\begin{array}{l}1012 \\
(185)\end{array}$ & $\begin{array}{l}2.20 \\
(5.29)\end{array}$ \\
\hline & Priming & 30 & 2.68 & -22 & 1.02 & -4 & 0.29 & -43 & 4.15 & -20 & -1.37 \\
\hline M-OPShift & Related & 563 & 1.25 & 1144 & 5.08 & 1403 & 7.63 & 1093 & 6.57 & 935 & 1.05 \\
\hline
\end{tabular}




\begin{tabular}{|c|c|c|c|c|c|c|c|c|c|c|c|}
\hline & \multicolumn{2}{|c|}{$\begin{array}{ll}(66) \quad(2.59)\end{array}$} & \multicolumn{2}{|c|}{$\begin{array}{ll}(331) & (8.55)\end{array}$} & (379) & $(10.61)$ & \multicolumn{2}{|c|}{$\begin{array}{ll}(225) & (9.03)\end{array}$} & $(165)$ & $(2.56)$ \\
\hline & \multirow{2}{*}{ Unrelated } & 600 & 3.33 & 1165 & 6.97 & 1427 & 8.35 & 1097 & 8.83 & 971 & 3.71 \\
\hline & & (72) & $(4.65)$ & $(327)$ & $(7.78)$ & $(368)$ & $(9.77)$ & $(235)$ & $(7.35)$ & $(158)$ & (4.69) \\
\hline & Priming & 37 & 2.08 & 21 & 1.88 & 24 & 0.72 & 4 & 2.26 & 36 & 2.66 \\
\hline \multirow{5}{*}{ Orthographic } & & 615 & 5.00 & 1242 & 8.37 & 1517 & 9.82 & 1115 & 9.21 & 1093 & 6.07 \\
\hline & Neratus & (67) & $(4.84)$ & $(309)$ & $(9.55)$ & $(306)$ & $(10.29)$ & $(221)$ & $(10.36)$ & $(183)$ & $(7.82)$ \\
\hline & & 631 & 4.17 & 1233 & 8.95 & 1505 & 10.87 & 1105 & 8.55 & 1090 & 7.43 \\
\hline & & (62) & $(4.52)$ & $(326)$ & $(9.05)$ & $(356)$ & $(10.46)$ & $(216)$ & $(7.86)$ & (198) & $(8.74)$ \\
\hline & Priming & 16 & -0.83 & -9 & 0.58 & -12 & 1.04 & -10 & -0.66 & -4 & 1.36 \\
\hline
\end{tabular}


Table 4

Experiment 2: Children's mean Chronological Age (CA), Reading Age (RA) and nonverbal reasoning abilities (Raven) as a function of Grade (standard deviations are shown in parentheses).

\begin{tabular}{llll}
\hline & CA (year; month) & RL (year; month) & Raven (raw score) \\
\hline Grade 3 $(n=20)$ & $8 ; 6(7$ months $)$ & $8 ; 8(13$ months $)$ & $30.74(2.92)$ \\
Grade $4(n=22)$ & $9 ; 7$ (6 months) & $9 ; 8(17$ months $)$ & $31.04(2.73)$ \\
Grade 5 $(n=22)$ & $10 ; 10(6$ months $)$ & $10 ; 6(16$ months $)$ & $32.38(3.20)$ \\
\hline
\end{tabular}


Table 5

Experiment 2 (250-ms prime duration): Mean reaction times (RT in $\mathrm{ms}$ ), error percentages (Err \%) and priming effects (unrelated - related priming) as a function of priming, condition and group (standard deviations are shown in parentheses)

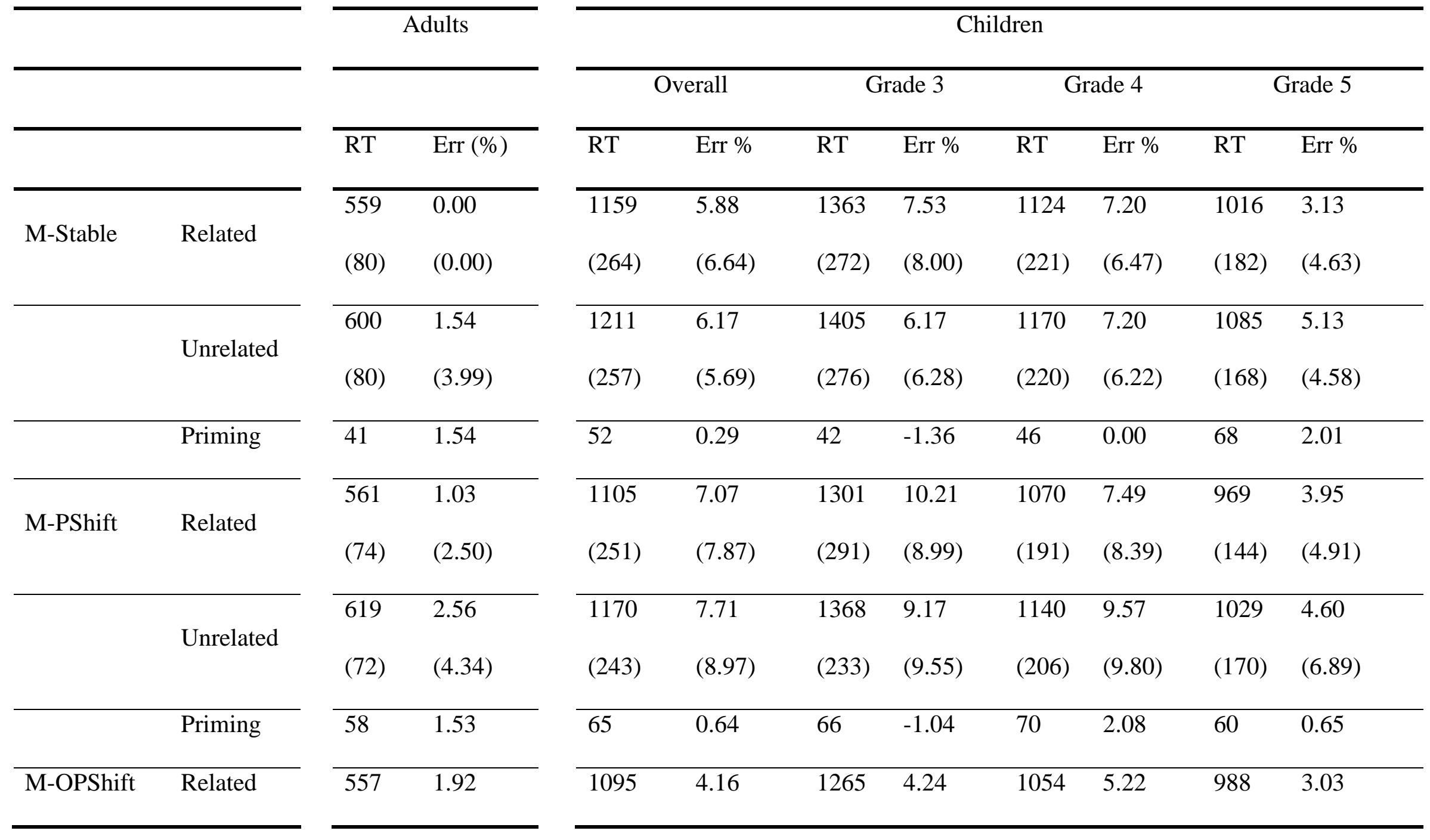




\begin{tabular}{|c|c|c|c|c|c|c|c|c|c|c|c|}
\hline & & (67) & $(3.00)$ & $(246)$ & $(5.45)$ & $(231)$ & $(5.55)$ & $(242)$ & $(6.22)$ & $(187)$ & $(4.47)$ \\
\hline & Unrelated & $\begin{array}{l}588 \\
(61)\end{array}$ & $\begin{array}{l}0.96 \\
(3.47)\end{array}$ & $\begin{array}{l}1173 \\
(259)\end{array}$ & $\begin{array}{l}5.26 \\
(7.11)\end{array}$ & $\begin{array}{l}1373 \\
(261)\end{array}$ & $\begin{array}{l}6.47 \\
(10.21)\end{array}$ & $\begin{array}{l}1126 \\
(224)\end{array}$ & $\begin{array}{l}5.22 \\
(5.44)\end{array}$ & $\begin{array}{l}1047 \\
(186)\end{array}$ & $\begin{array}{l}4.26 \\
(5.28)\end{array}$ \\
\hline & Priming & 31 & -0.96 & 78 & 1.10 & 108 & 2.23 & 72 & 0.00 & 59 & 1.23 \\
\hline Orthographic & Related & $\begin{array}{l}642 \\
(83)\end{array}$ & $\begin{array}{l}4.81 \\
(4.53)\end{array}$ & $\begin{array}{l}1204 \\
(229)\end{array}$ & $\begin{array}{l}9.88 \\
(9.34)\end{array}$ & $\begin{array}{l}1337 \\
(263)\end{array}$ & $\begin{array}{l}14.71 \\
(10.27)\end{array}$ & $\begin{array}{l}1178 \\
(186)\end{array}$ & $\begin{array}{l}9.18 \\
(9.63)\end{array}$ & $\begin{array}{l}1115 \\
(189)\end{array}$ & $\begin{array}{l}6.41 \\
(6.34)\end{array}$ \\
\hline & Unrelated & $\begin{array}{l}661 \\
(105)\end{array}$ & $\begin{array}{l}4.33 \\
(4.69)\end{array}$ & $\begin{array}{l}1212 \\
(222)\end{array}$ & $\begin{array}{l}8.50 \\
(7.60)\end{array}$ & $\begin{array}{l}1380 \\
(259)\end{array}$ & $\begin{array}{l}13.34 \\
(6.50)\end{array}$ & $\begin{array}{l}1184 \\
(157)\end{array}$ & $\begin{array}{l}7.99 \\
(8.27)\end{array}$ & $\begin{array}{l}1095 \\
(151)\end{array}$ & $\begin{array}{l}4.85 \\
(5.51)\end{array}$ \\
\hline & Priming & 19 & -0.48 & 8 & -1.37 & 43 & -1.37 & 6 & -1.19 & -20 & -1.56 \\
\hline
\end{tabular}

